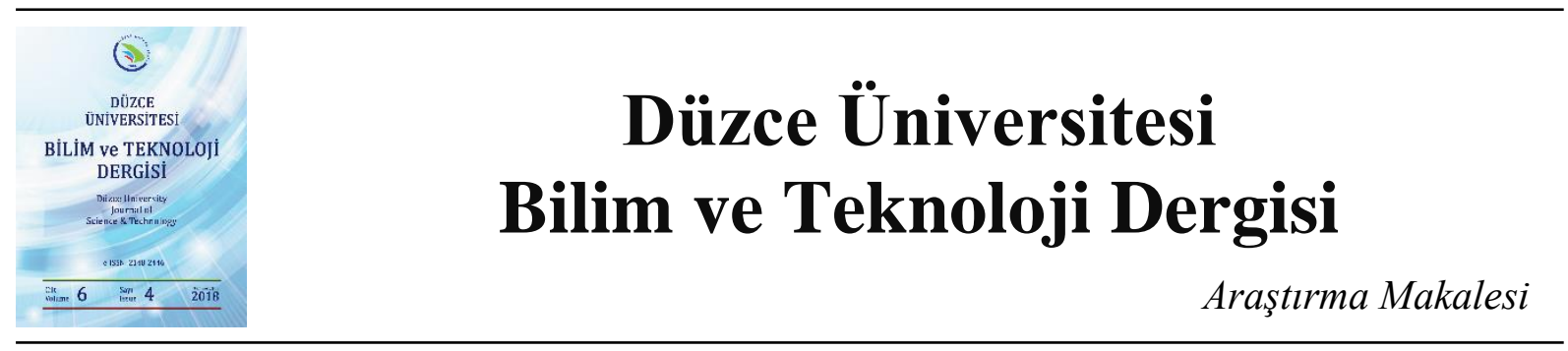

\section{Östenitik Paslanmaz Çelik ile Düşük Karbonlu Çeliğin Kaynak Edilebilirliğinin Araştırılması ve Kaynak Parametrelerinin Optimizasyonu}

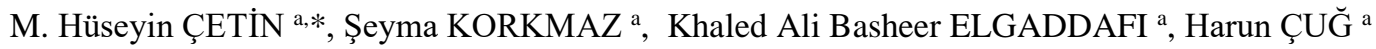 \\ ${ }^{a}$ Makine Mühendisliği Bölümü, Mühendislik Fakültesi, Karabük Üniversitesi, Karabük, TÜRKIYE \\ * Sorumlu yazarın e-posta adresi: hcetin@karabuk.edu.tr
}

\begin{abstract}
ÖZET
Bu çalışmada, östenitik paslanmaz çelik (AISI 304) ve düşük karbonlu çelik (S235JR) malzemenin gaz metal ark kaynak yöntemi kullanılarak farklı akım-voltaj (kaynak enerjisi) değerleri ve tel besleme hızlarında kaynak edilebilirliği araştırılmıştır. Kaynaklı numunelere çekme testi ve sertlik deneyleri yapılarak birleştirilen malzemelerin mekanik özellikleri incelenmiş, sonuçlar Taguchi ve varyans analizi (ANOVA) metodu kullanılarak değerlendirilmiştir. Ayrıca kaynak bölgesinin mikroyapısı incelenerek, 1sı tesiri altındaki bölgenin (ITAB) sertlik davranışı açıklanmaya çalışılmıştır. Çekme deneyi sonuçlarına göre deformasyon, kaynak bölgesi dışında, düşük karbonlu çelik bölgesinde meydana gelmiş̧ir. Sertlik değerlerinin analizinde enerji girdisi artışının sertliği azalttığı, tel besleme hızındaki artışın ise sertliği artırdığı belirlenmiştir. Mikroyapı çalışmaları sonucunda, kaynak bölgesinde tane büyümesinin meydana geldiği tespit edilmiştir. ANOVA sonuçlarına göre kaynak bölgesi enerji miktarı ve tel besleme hızı parametreleri kaynak bölgesinin sertlik davranışını \%70 oranında açıklayabilmektedir.
\end{abstract}

Anahtar Kelimeler: Kaynak edilebilirlik, AISI 304, S235JR, Kaynak parametreleri

\section{Investigation of Weldability of Austenitic Stainless Steel and Low Carbon Steel and Optimization of Welding Parameters}

\begin{abstract}
In this study, weldability of austenitic stainless steel (AISI 304) and low carbon steel (S235JR) by using gas metal arc welding method under different current-voltage (welding energy) values and wire feed speeds were investigated. The mechanical properties of the joined materials were examined by carrying out tensile tests and hardness tests to the welded specimens and the results were evaluated using Taguchi and analysis of variance (ANOVA) method. In addition, the microstructure of the weld zone was examined and the hardness behavior of the heat affected zone (HAZ) was tried to be explained. According to the tensile test results, deformation was occured in low carbon steel zone outside of welding zone. In the analysis of hardness values, it was determined that increase of energy input decreased hardness and increase of wire feed rate increased hardness. As a result of
\end{abstract}


the microstructure studies, it was observed that the grain growth phenomenon occurred in the welding zone. According to the ANOVA results, the amount of energy in the welding zone and the wire feed rate parameters can explain $70 \%$ of the hardness behavior of the welding zone.

Keywords: Weldability, AISI 304, S235JR, Welding parameters

\section{GiRIS}

$\mathrm{E}$ ndüstriyel malzeme seçiminde ekonomiklik ve temin edilebilirlik faktörlerinin önem kazanması farklı malzemelerin birlikte kullanılmasını gerektirmektedir. Bu durum farklı malzemelerin birlikte imal edilebilirliğinin araştırılması ihtiyacını ortaya çıkarmaktadır. Metal malzeme odaklı imalat sektörünün büyüklüğü göz önüne alındığında, özellikle farklı metal alaşımlarının kaynak edilebilirliği konstrüktif açıdan büyük önem taşımaktadır. Literatür incelendiğinde farklı alüminyum alaşımlarının kaynak edilebilirliği üzerine çok sayıda çalışma bulunduğu görülmektedir [1]. Buna karşın farklı alaşım özelliklerine sahip çelik malzemelerin kaynağı konusunda detaylı araştırmaların yapılması gerekmektedir.

İyi bir konstrüksiyondan; mukavemetinin yüksek olması, korozyona dirençli olması, kolay işlenebilmesi, hafif ve ekonomik olması beklenir. Konstrüksiyondan beklenilen bu özellikler, farklı mekanik üstünlüklere sahip malzemelerin uygun bir şekilde birleştirilmesini zaruri hale getirmektedir. Örneğin; uçak tasarımında en önemli faktörler ağıllık, maliyet ve mukavemettir. Tek çeşit malzemeyle bu faktörleri bir arada elde etmek mümkün değildir. Dolayısıyla farklı özeliklere sahip malzemelerin birleştirilmesi, tasarımın mekanik açıdan istenilen özellikleri sağlamasının yanı sıra maliyetin de kayda değer oranda düşmesini sağlayacaktır. Ancak farklı metallerin birleştirilmesi, kaynak yapılan metallerin fiziksel, mekanik ve metalurjik özelliklerinin farkından dolayı zordur [2]. Ayrıca kaynaklı bağlantıların kaynak bölgesinin mekanik özellikleri genellikle emniyetli taşınabilecek yükü ve yorulma ömrünü sınırlar niteliktedir [3]. Bu nedenle kaynak bağlantılarının kusursuz olması konstrüksiyonun genel dayanımı açısından büyük öneme sahiptir. Farklı özelliklerdeki malzemelerin kaynağında, ITAB'da çatlama, kalıcı kaynak gerilmeleri, bölgesel yığılma, basma ve çekme ısıl gerilmeleri, gerilimli korozyon çatlaması vb. çeşitli sorunlar ortaya çıkmaktadır [4]. Bu sorunlar kaynak kalitesini ve kaynaklı birleşimi sağlanan malzemelerin mekanik özelliklerini büyük ölçüde etkileyen unsurlardır. $\mathrm{Bu}$ etkenlerin minimum seviyeye indirgenmesi için kaynak kalitesinin belirlenmesinde optimum giriş parametrelerinin seçimi önemli rol oynamaktadır [5].

Kumar ve arkadaşları [5], paslanmaz ve düşük karbonlu çeliğin kaynak edilebilirliğini Taguchi yöntemi kullanarak araştırmışlardır. Giriş parametresi olarak kaynak akımı, kaynak voltajı ve gaz debisi parametreleri kullanılmış, çıkış parametresi olarak da kaynak bölgesinin sertliği ölçülmüştür. Çalışma, kaynak bölgesi sertliğine göre parametre analizi açısından anlamlı olsa da, kaynak nüfuziyetinin yeterliliği hakkında bilgi vermemektedir. Kaynak işleminin yeterliliğinin ölçülmesi için ilave mekanik testlere ihtiyaç duyulmaktadır. Patel [4], düşük karbonlu çelik ve AISI 409 paslanmaz çeliğinin kaynak edilebilirliğinde çekme testi uygulayarak optimum kaynak parametrelerini araştırmıştır. Giriş parametresi olarak gaz basıncı, akım ve voltaj kullanılmış, çıkış parametresi olarak da çekme mukavemeti ölçülmüştür. Gaz basıncı, akım ve voltaj parametrelerinin çekme dayanımı 
üzerinde surasıyla \%1.65, \%18.09 ve \%74.56 oranında etkili olduğu analiz edilmiştir. Çalışmada, seçilen giriş parametrelerinden gaz basıncının çekme mukavemeti üzerinde istatistiki olarak anlamlı bir etkisinin bulunmadığı görülmüştür. Bu parametre kaliteli kaynak bağlantısı için belirleyici faktör değildir. Çalışmada çekme testi sebebiyle oluşan deformasyonun hangi bölgede oluştuğu hakkında yeterli bilgi bulunmamaktadır. $\mathrm{Bu}$ sebeple kaynak parametrelerinin kaynak edilebilirliğe etkisi hakkında anlamlı bir sonuca ulaşılamamaktadır. Tewari ve arkadaşları [6], kaynak parametrelerinin düşük karbonlu çelik malzeme üzerindeki etkisini metal ark kaynağı kullanarak araştırmışlardır. Giriş parametresi olarak kaynak akımı, kaynak voltajı ve kaynak hızı kullanılmış, çıkış parametresi olarak da penetrasyon derinliği ölçülmüştür. Çalışma, çıkış parametresi olarak tek bir parametrenin incelenmesi ve malzeme olarak sadece düşük karbonlu çeliğin kullanılmış olması sebebiyle, parametrelerin farklı malzemeler üzerindeki etkisi hakkında bilgi vermemektedir. Kahraman ve arkadaşları [7] , östenitik paslanmaz çelik ve düşük karbonlu çeliğinin kaynak edilebilirliğini, ark kaynağı yöntemiyle farklı elektrodlar kullanarak incelemişlerdir. Çekme, eğme, sertlik testleri uygulanmıştır. Çalışmada sadece farklı elektrodların etkisi incelenmiş, diğer kaynak parametreleri analiz edilmemiştir. Ayrıca sonuçlar nitel olarak değerlendirilmiş, nicel sonuç veren istatistiki bir analiz yapılmamıştır. Kılınçer ve arkadaşları [2], ferritik paslanmaz çelik ve düşük karbonlu çeliğin MIG kaynak yöntemiyle kaynak edilebilirliğinin mekanik özelliklere etkisi araştırmışlardır. Çalışmada, çekme, eğme, sertlik ve çentik darbe testleri uygulanmıştır. Çalışma sonucunda, ITAB bölgesinde tane irileşmesi olduğu ve deformasyonun düşük karbonlu çelik malzemede gerçekleştiği görülmüştür.

Jogi ve arkadaşları [8], AISI 1018 yumuşak çeliğinin MIG kaynağı için optimum parametrelerini öğretim-öğrenim tabanlı optimizasyon algoritmasını kullanarak araştırmışlardır. Giriş parametresi olarak kaynak akımı, iş parçası kalınlığı, voltaj ve tel besleme hızı kullanılmıştır. Çalışmada Taguchi'nin L27 ortogonal dizisinden yararlanılmış, matematiksel modeller geliştirilmiştir. Çıkış parametresi olarak penetrasyon derinliği ve kaynak dikişi genişliği incelenmiştir. Giriş̧ parametrelerinin çıkış parametrelerine etkisi numuneler üzerinde açıkça görülmekte olup bu etki oluşturulan matematiksel modellerle uyumluluk göstermiştir. Bu durum, giriş parametrelerinin AISI 1018 yumuşak çeliği için MIG kaynak yönteminin kalitesinde istatistiksel olarak anlamlı olduğunu göstermiştir. Prasad ve Namala [9], AA5083 ve AA6061 malzemelerinin sürtünme kaynağı ile birleştirilmesindeki optimum parametreleri ANOVA kullanarak araştırmışlardır. Çalışmada giriş parametresi olarak takım dönme hızı, kaynak hızı ve takım eğme açısı kullanılmış, çıkış parametresi olarak da kaynaklı numunelerin yüzde uzama ve sertlik değerleri ölçülmüştür. Deneyler Taguchi'nin L9 ortogonal dizisine göre yapılmıştır. Sonuçlar incelendiğinde, giriş parametrelerinin sertlik ve yüzde uzama değerlerini önemli derecede etkilediği ve kaynak kalitesinin iyileştirilmesi için gerekli optimum giriş parametresi değerlerinin birbirleriyle uyumlu olduğu görülmüştür. Zhou ve arkadaşları [10], AA6061 alüminyum alaşımlı levha ile saf titanyum levhanın ultrasonik punta kaynağı ile birleştirilmesinde optimum parametreleri araştırmışlardır. Giriş parametresi olarak kaynak süresi kullanılarak kaynaklı numunelerin mekanik özellikleri ve mikroyapısı incelenmiştir. Mekanik özellikler çekme ve sertlik deneyleriyle test edilmiş, mikroyapılarda oluşan fazlar optik mikroskop ve XRD (x 1şını kırınım yöntemi) ile incelenip analiz edilmiştir. Sertlik testi sonuçları, kaynak süresinin malzemelerin sertliği üzerinde anlamlı bir etkisinin olmadığını, çekme testi sonuçları ise kopmaların kaynaklı bağlantıların ara yüzeylerinde meydana geldiğini göstermiştir. Bunun yanı sıra, kaynak süresinin çok düşük ya da çok yüksek olması malzemelerin ve kaynaklı bağlantının mekanik özelliklerini olumsuz etkilediği görülmüştür. Çalışmada istatistiki bir analiz yapılmamış, sonuçlar sadece nitel olarak değerlendirilmiştir. Ayrıca giriş parametresi olarak tek bir parametrenin incelenmiş olması optimum parametrelerin belirlenmesinde yeterli bilgi vermemektedir. Ghosh ve arkadaşları [11], AISI409 ferritik paslanmaz çeliğinin MIG kaynağ1 ile birleştirilmesinde kaynak kalitesi için 
optimum parametrelerini Taguchi metoduyla araştırmışlardır. Giriş parametresi olarak kaynak akımı, kaynak akış hızı, levhanın ucu ve merkezi arasındaki mesafe kullanılmış, çıkış parametresi olarak çekme gerilmesi ve yüzde uzama değerleri ölçülmüştür. Ayrıca zamanda yüzey ve alt yüzey kusurları incelenmiştir. Çalışmada mekanik özelliklerin incelenmesi için çekme testi yapılmış, yüzey ve alt yüzey kusurlarının incelenmesi için de görsel inceleme ve x 1şını radyografik testi uygulanmıştır. $\mathrm{X}$ 1şını radyografik testi ve görsel inceleme sonucunda, numunede penetrasyon eksikliğinin, düşük seviyede gözenek oluşumunun ve kaynak çöküntülerinin meydana geldiği görülmüştür. Çekme testi sonucunda ise optimum parametrelerin, çekme mukavemeti ve yüzde uzama değerlerini en üst seviyeye çıkardığı görülmüştür. Doğrulayıcı deney sonuçları Taguchi yöntemiyle elde edilen sonuçların uyumlu olduğunu göstermiştir. $\mathrm{Bu}$ durum, ferritik paslanmaz çeliğin MIG kaynağı işleminde optimum parametreleri belirlemek için Taguchi deneysel tasarım yönteminin en uygun yöntemlerden biri olduğunu göstermektedir.

Bu çalışmanın özgün değeri; kaynak parametrelerinin S235JR düşük karbonlu çelik ile AISI 304 paslanmaz çeliğin kaynak edilebilirliği üzerine etkilerinin deneysel olarak analizidir. Kaynak parametresi olarak kaynak akımı, ark voltajı (kaynak enerjisi) ve besleme hızı dikkate alınmıştır. Parametrelerin analizi için kaynak bölgesinin mekanik davranışı çekme testi ve sertlik ölçümü (Vickers sertliği - HV) yöntemiyle incelenmiştir. Ayrıca, kaynak bölgelerinin mikro yapısı da incelenerek deney sonuçları analiz edilmiştir. Çekme testinde; akma ve çekme mukavemeti değerleri ile birim uzamalar dikkate alınmıştır. Deneysel tasarım ve analiz için Taguchi yöntemi ile varyans analizi (ANOVA) kullanılmıştır.

\section{MALZEME Ve Metot}

Çalışma kapsamında Tablo 1'de kimyasal bileşimleri verilen AISI 304 östenitik paslanmaz çelik ve S235JR düşük karbonlu çelik malzemeleri kullanılmıştır. $460 \mathrm{MPa}$ akma ve $600 \mathrm{MPa}$ çekme dayanımına sahip çelik tel elektrot malzeme kullanılarak gaz metal ark kaynak (MIG) yöntemiyle birleştirme işlemi gerçekleştirilmiştir. Malzemeler Tablo 2'de verilen kaynak parametreleri kullanılarak birleştirilmiştir.

Kaynak işleminde kaynak bölgesi için 3 farklı enerji miktarı ve tel besleme hızı parametresi kullanılmıştır. Tam faktöriyel tasarıma göre 9 farklı deney oluşturulmuş ve sertlik değeri analizinde Taguchi yaklaşımına göre (en yüksek en iyidir yaklaşımı) parametre analizi ve optimizasyon çalışması gerçekleştirilmiştir. Optimizasyon için istatistiki bir ölçüt olan "sinyal/gürültü (S/N)" oranı dikkate alınmıştır. S/N oranı ne kadar büyükse analiz yapılan değer de o derece istatistiki olarak anlamlılık içermektedir. Ayrıca sertlik değerleri varyans analizine tabi tutularak deney parametrelerinin nicel olarak etki değerleri belirlenmiştir. Kaynak bölgesine aktarılan enerjinin hesabı için Eşt. 1 kullanılmıştır. Eşt. 1'de "V" ark voltajını, "I" kaynak akımını "s" ise saniye cinsinden zamanı temsil etmektedir. Birleştirilen iş parçası 200x400x2 mm boyutlarındadır. Parçalar kaynak işlemine tabi tutulduktan sonra, parçalar üzerinden “TS 287 EN 895” standardına göre belirlenen ölçülerde 3'er adet çekme numunesi çıkartılmıştır (Şekil 1). Ayrıca paslanmaz çelik ve düşük karbonlu çelik için de ayrı ayrı çekme numuneleri elde edilerek çekme deneyleri gerçekleştirilmiştir (Şekil 2). Çekme numunesi çıkartılması esnasında 1sıl etki oluşmaması için su jeti tezgâhı ile kesme işlemi gerçekleştirilmiştir. 
Tablo 1. Malzemelerin kimyasal bileşimleri

\begin{tabular}{lllllllll}
\hline Malzeme & $\mathrm{C}$ & $\mathrm{Mn}$ & $\mathrm{Si}$ & $\mathrm{P}$ & $\mathrm{S}$ & $\mathrm{Cr}$ & $\mathrm{Ni}$ & $\mathrm{Nb}$ \\
\hline AISI 304 & 0,025 & 1,9 & 0,2140 & 0,02 & 0,022 & 19,28 & 8,46 & 0,022 \\
\hline S235JR & 0,091 & 0,503 & 0,152 & 0,015 & 0,006 & 0,018 & 0,05 & $<0,001$ \\
\hline
\end{tabular}

Tablo 2. Kaynak parametreleri

\begin{tabular}{cccccc}
\hline \multicolumn{2}{c}{ ITAB Bölgesine Aktarılan Enerji } & Tel Besleme Hızı & Kaynak Kalınlığı \\
\hline $\begin{array}{c}\text { Akım } \\
(A)\end{array}$ & $\begin{array}{c}\text { Voltaj } \\
(\mathrm{V})\end{array}$ & $\begin{array}{c}\text { Kaynak } \\
\text { Süresi }(\mathrm{s})\end{array}$ & $\begin{array}{c}\text { Enerji } \\
(\mathrm{kJ})\end{array}$ & $(\mathrm{mm} / \mathrm{s})$ & $(\mathrm{mm})$ \\
\hline 90 & 18,8 & 30 & 50,76 & 7 & 10 \\
\hline 120 & 20,6 & 30 & 74,16 & 12 & 10 \\
\hline 170 & 23,4 & 30 & 119,34 & 18 & 10 \\
\hline
\end{tabular}

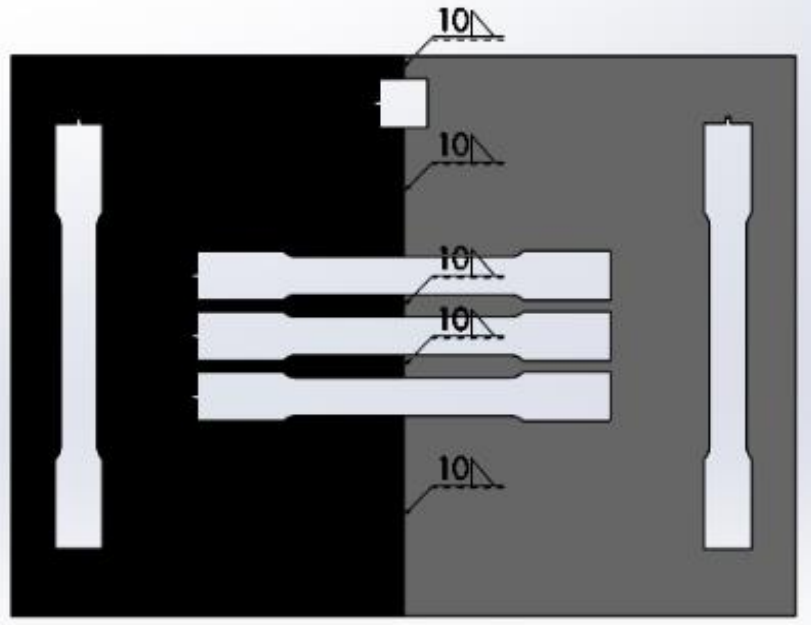

Şekil 1. Kaynaklanan ve üzerinden çekme numuneleri çıkartılan parçaya ait teknik resim

Kaynak Enerjisi $=$ V. I. $\mathrm{s}$

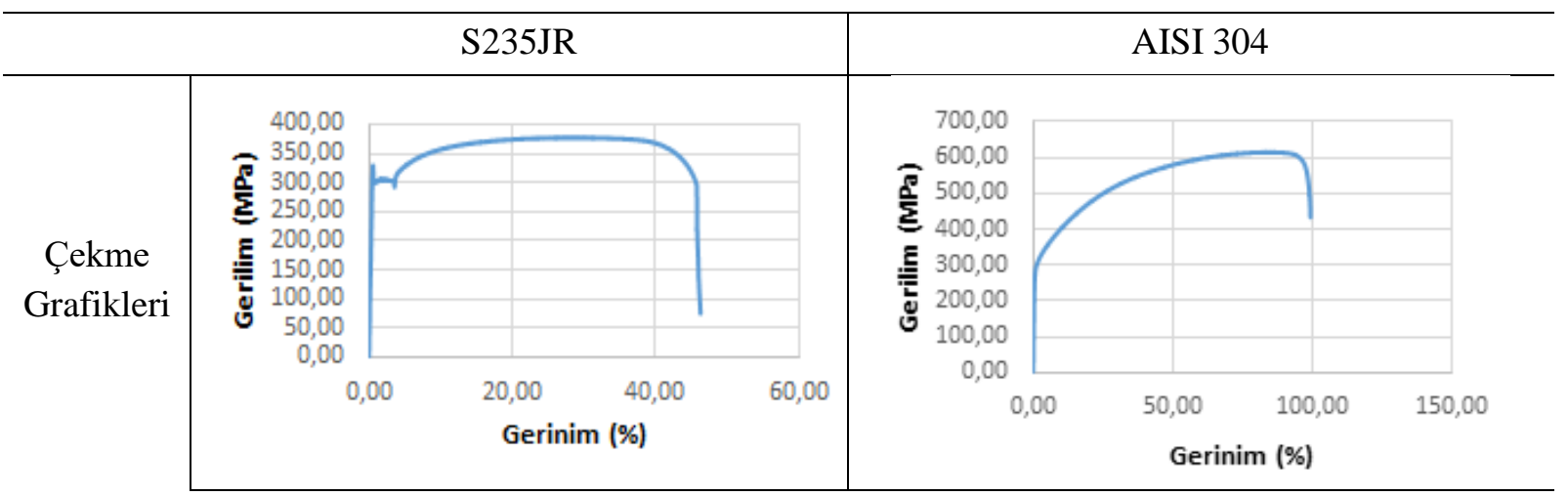




\begin{tabular}{c|c}
\cline { 2 - 3 } Akma dayanımı: $303,55 \mathrm{MPa}$ & Akma dayanımı: 276,23 MPa \\
Çekme dayanımı: $377,90 \mathrm{MPa}$ & Çekme dayanımı: $614,55 \mathrm{MPa}$ \\
Yüzde Uzama: \% 14,9 & Yüzde Uzama: \% 31,06 \\
\hline
\end{tabular}

Şekil 2. S235JR ve AISI 304 için deney numunelerinden elde edilen çekme grafikleri.

Kaynaklı numunelerin mekanik özellikleri, çekme ve sertlik testleri ile incelenmiştir. Çekme testi Zwick/Roell Z600 Universal Test Cihazı kullanılarak oda sıcaklığında TS EN ISO 6892-1 standardına uygun olarak gerçekleştirilmiştir. Vickers mikro sertlik (HV) testi, Q250 M Universal Sertlik Ölçüm Cihazı kullanılarak 15 saniye süreyle $0,5 \mathrm{~kg}$ yük uygulanarak yapılmıştır. Numunelerin mekanik özellikleri ile birlikte mikroyapı analizleri de gerçekleştirilmiştir. Numunelerin mikroyapı analizi için Şekil 3'te belirtilen aşamalar gerçekleştirilmiştir.

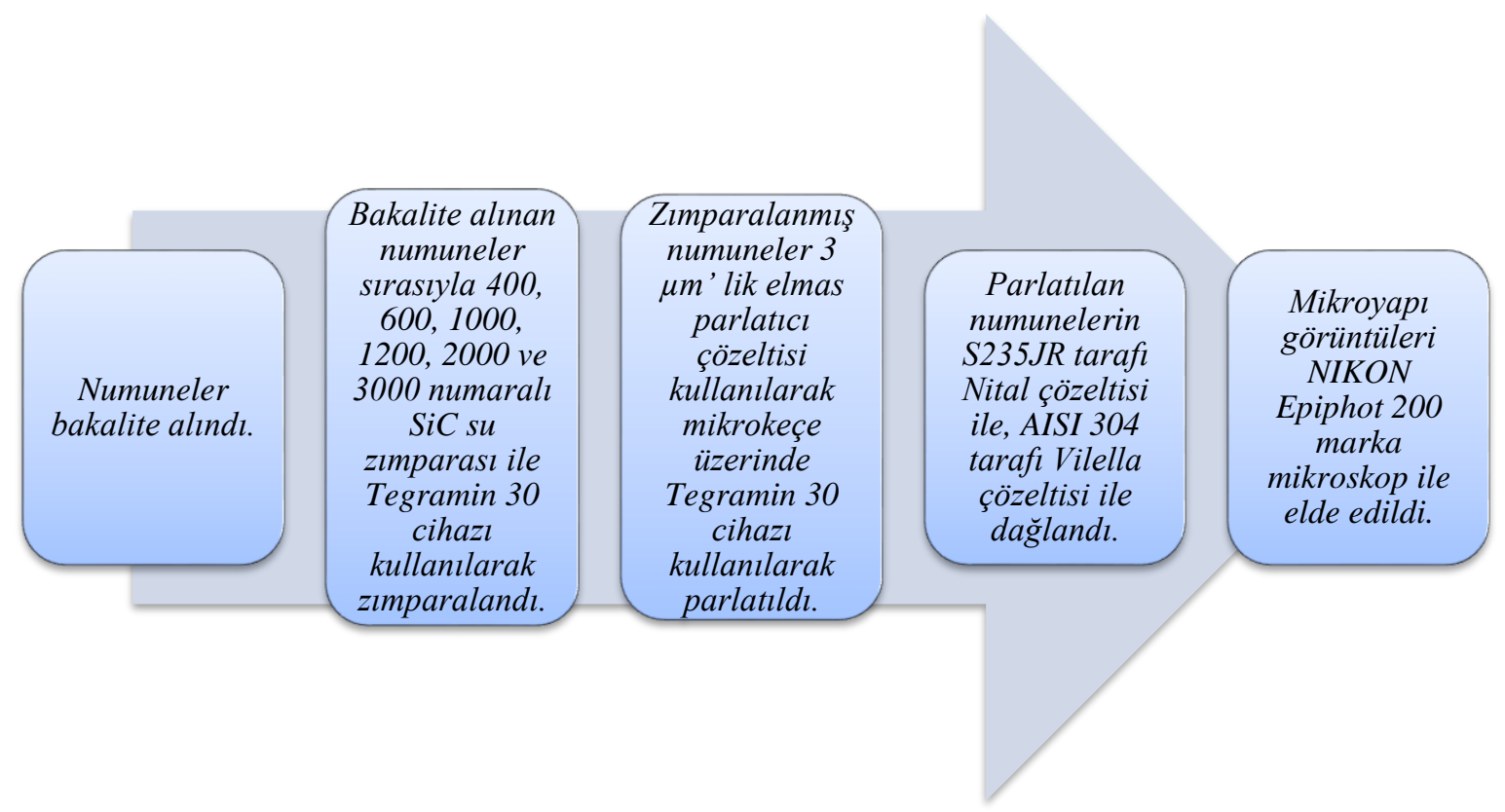

Şekil 3. Mikroyapı analizi numunesi hazırlama için işlem adımları.

\section{TARTIȘMA VE SONUC}

Kaynak bölgesinin dayanımının analizi için çekme testleri gerçekleştirilmiştir. İlk olarak sadece S235JR ve AISI 304 malzemelerin çekme testleri gerçekleştirilmiş ve elde edilen sonuçlar Şekil 2'de verilmiştir. S235JR malzemenin akma-çekme değerleri sırasıyla yaklaşık $300 \mathrm{MPa}-380 \mathrm{MPa}$ olarak, AISI 304 malzemenin akma-çekme değerleri ise sırasıyla yaklaşık $280 \mathrm{MPa}-615 \mathrm{MPa}$ olarak ölçülmüştür. Kaynaklı numunelerin çekme deney sonuçları Tablo 3'te verilmiştir. Kaynaklı numunelerde ölçülen akma-çekme mukavemeti değerleri sırasıyla yaklaşı $280 \mathrm{MPa}-380 \mathrm{MPa}$ değerlerinde ölçülmüştür (Tablo 3). Kaynaklı numunelerin gözle incelenmesinde, bütün deney şartlarında S235JR malzeme bölgesinde kopma hasarının oluştuğu (Tablo 3), kaynaklı bölgede ve paslanmaz çelik malzeme bölgesinde herhangi bir kusur oluşmadığı belirlenmiştir. S235JR malzemenin çekme dayanımının düşük olması sebebiyle deformasyonlar düşük karbonlu çelik malzeme bölgesinde gerçekleşmiştir. Çekme deneyi sırasında kopma, gevrek kırılma özelliklerine sahip malzemelerde meydana gelmektedir [10]. Deformasyona uğramış kaynaklı bir numuneye ait detaylı görüntü Şekil 4'te verilmiştir. Bu durum, farklı malzemelerin kaynak edilebilirliğinin mümkün 
olduğunu göstermektedir [2]. Kaynaklı bölgede deformasyon oluşmaması, hem kaynak parametrelerinin doğru seçildiğini hem de farklı alaşımlara sahip çelik malzemelerin ITAB bölgesinde uygun faz oluşturabildiğini kanıtlamıştır. Çekme dayanımı yüksek paslanmaz çelik malzemenin ve kaynak telinin kaynak bölgesinde düşük karbonlu çelikle oluşturduğu kompozit malzeme, dayanım açısından düşük karbonlu çelikten daha yüksek mukavemet sağlayabilmiştir. Şekil 2 ve Tablo 3 'teki deney sonuçları akma dayanımı değerleri açısından incelendiğinde, farklı kaynak şartlarında belirgin bir değişiklik görülmemiştir. $\mathrm{Bu}$ sebeple, kaynak bölgesinin mekanik özelliklerinin değerlendirilmesinde akma dayanımının anlamlı bir etkisi olmadığı iddia edilebilir.

Tablo 3. Çekme ve sertlik deney sonuçları.

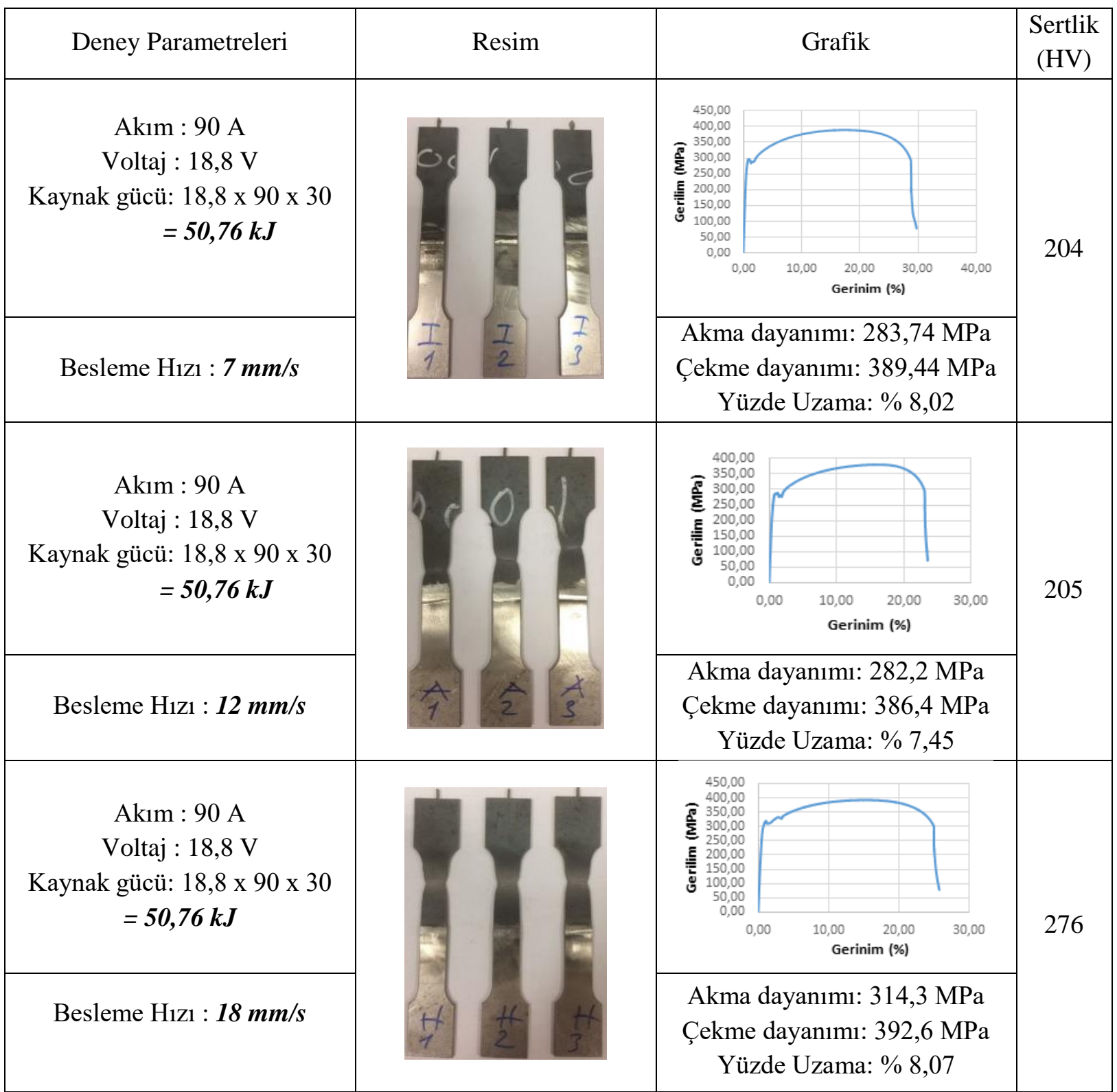




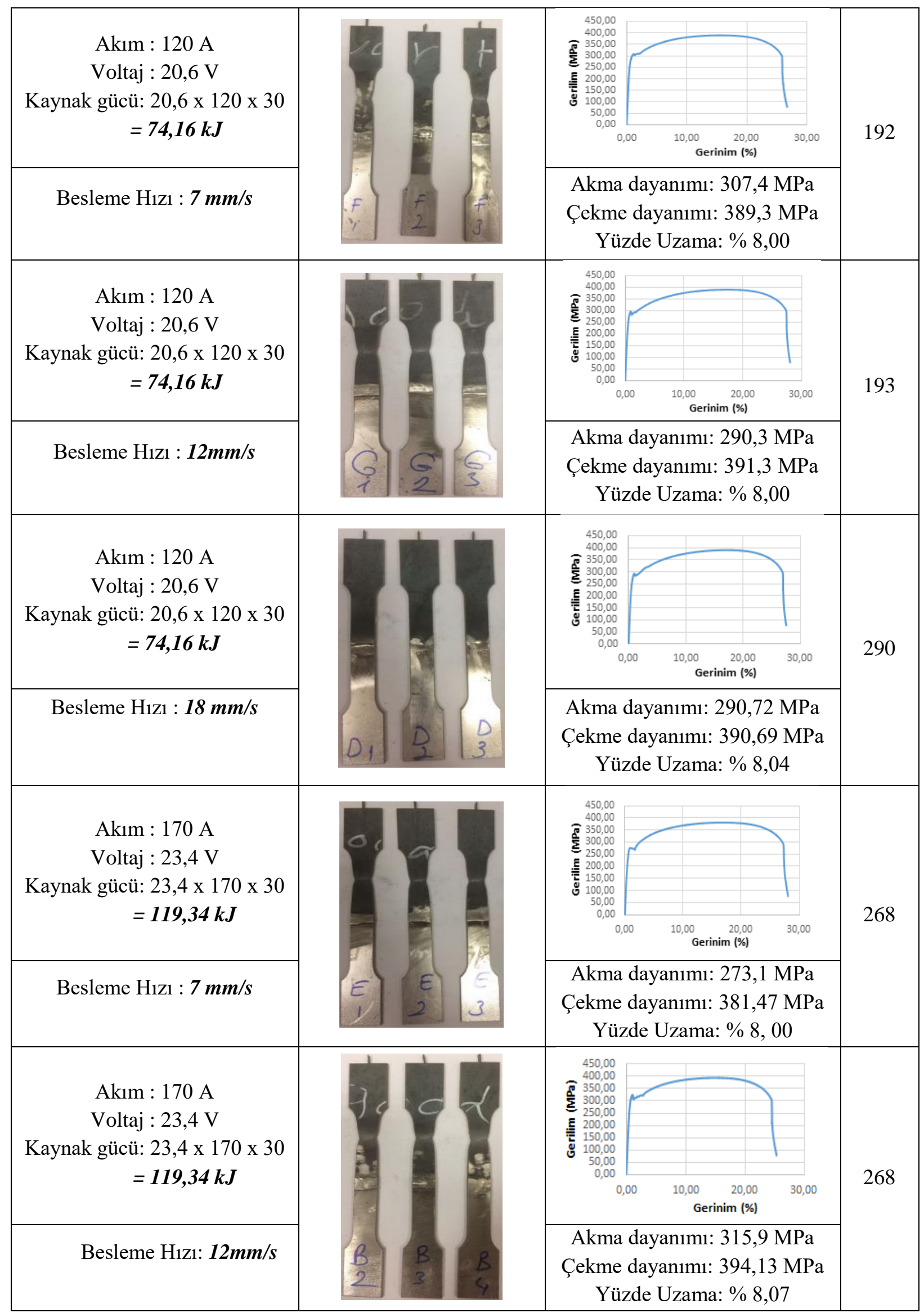




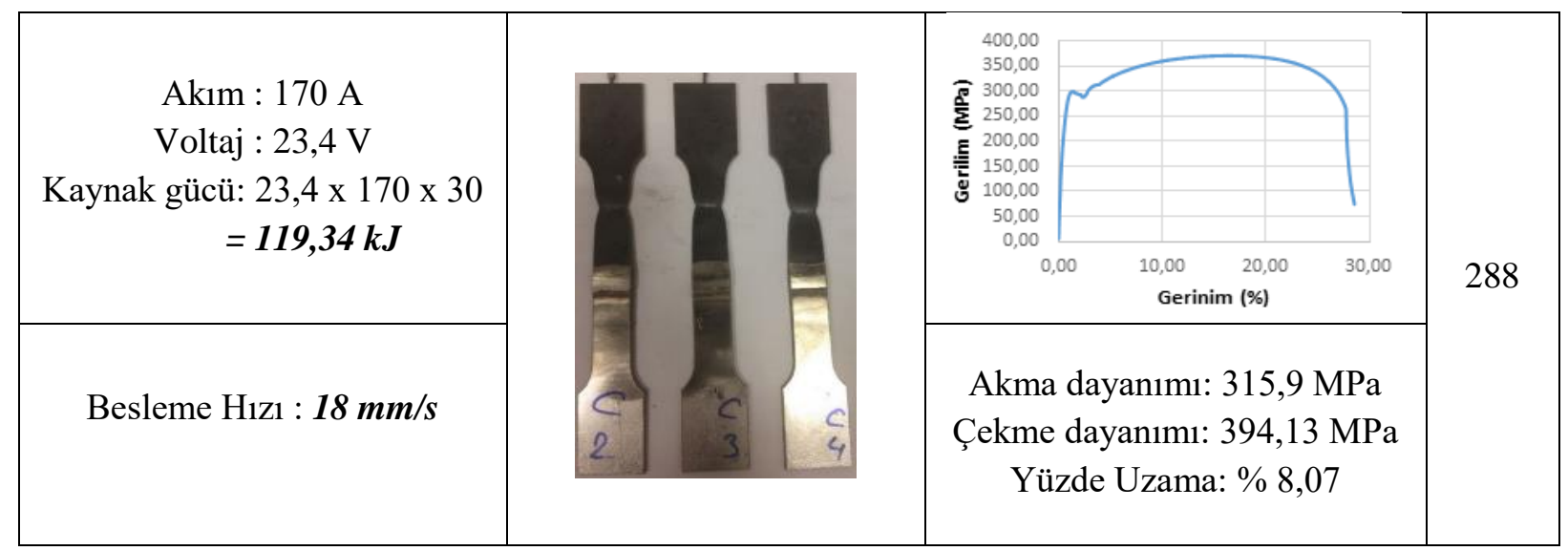

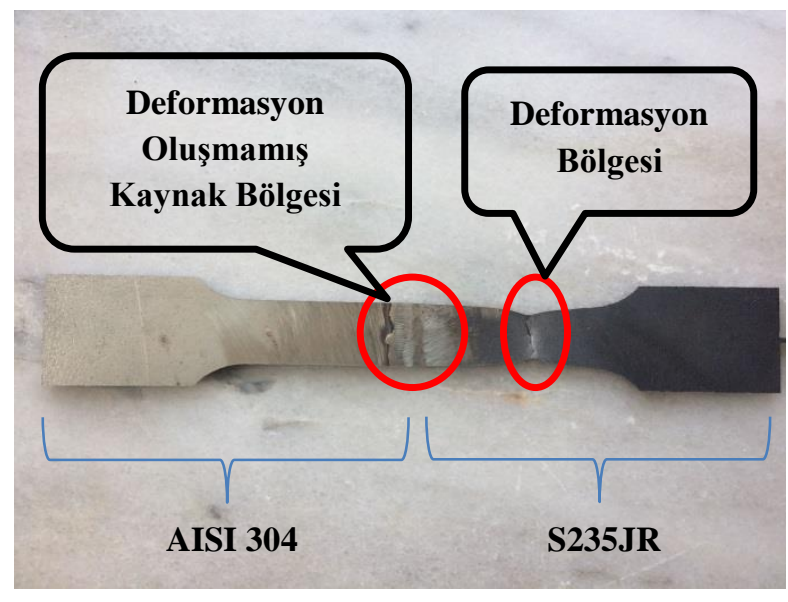

Şekil 4. S235JR bölgesinden deforme olmuş numune (enerji:74,16 kJ, besleme hızı:7 mm/s).

Tablo 3'te, yüzde uzama değerleri " $\Delta \ell / \ell$ " ( $\Delta \ell$ : Boy farkı, $\ell$ : İlk boy) bağıntısına bağlı olarak hesaplanmış ve uzama değerlerinin ihmal edilebilir sapmalarla $\% 8$ oranında gerçekleştiği görülmüştür. Bütün deney şartlarında deformasyon S235JR malzemede gerçekleşmiş ve Şekil 2'ye göre S235JR'nin birim uzamas $\% 14,9$ olarak gerçekleşmiştir. Bu durum kaynak işlemi sonrası birim uzamada ciddi bir değişimin gerçekleştiğini düşündürtmektedir. Fakat kaynak işlemi yapılan S235JR malzemenin boyu " $\ell / 2$ " uzunluğunda olup, çekme testine de sadece " $\ell / 2$ " uzunlukta S235JR malzeme tabi tutulmaktadır. Geri kalan " $\ell / 2$ " uzunlukta ise AISI 304 malzeme bulunmaktadır. Bu sebeple hesaplanan yüzde uzama değerleri yanlış yorumlamalara sebebiyet vermektedir. Literatürde de benzer hataların bulunduğu belirlenmiştir. Bu aşamada göze çarpan önemli bir diğer unsur ise yanlış hesaplama değerlerine rağmen yüzde uzama değerlerinin $\% 8$ olarak hesaplanmış olmasıdır. Normal şartlarda bu değerin $\% 7$ civarında çıkması beklenmektedir. \%1'lik birim uzama değeri sadece S235JR'de değil kaynak bölgesinde ve paslanmaz çelik numunede de kalıcı birim uzamaların oluştuğunu düşündürmektedir. S235JR malzemenin çekme dayanımı $377 \mathrm{MPa}$ olarak ölçülmüş ve malzeme deformasyona uğradığını göre bütün kaynak numunesi üzerine $377 \mathrm{MPa}$ 'lı gerilim etki etmiştir. AISI 304 malzemenin akma dayanımı $276 \mathrm{MPa}$ olarak ölçülmüştür (Şekil 2). Bu durumda AISI304 malzemede de plastik deformasyon oluşumu kaçınılmaz olarak gerçekleşmiştir. $\mathrm{Bu}$ sebeple ölçülen yüzde uzamaların değişiminin kaynaklanmış numuneye bağlı olarak yorumlanması güç olarak gözükmektedir.

Çekme deneylerinden farklı malzemelerin kaynak edilebilirliği kanıtlanmış fakat kaynak parametrelerinin kaynak bölgesine etkisi hakkında yeterli veri elde edilememiştir. Bu sebeple kaynak 
bölgesinin sertlik değerleri ölçülerek kaynak parametrelerinin proses üzerindeki etkileri analiz edilmeye çalış1lmıştır. Tablo 3'te verilen sertlik değerlerine göre proses parametreleri ile sertlik değerleri arasındaki ilişkiyi analiz edebilmek için ANOVA (Tablo 4) ve Taguchi yöntemi kullanılmıştır [9,11]. ANOVA sonuçlarına göre kaynak bölgesinin sertliği, kaynak bölgesine aktarılan enerji ve tel besleme hızı parametrelerine göre \%71 (Adj R-Sq) oranında açıklanabilmektedir (Tablo 4). \%29'luk açıklanamayan kısmın ise kaynak yöntemi, kaynak dikiş tipi, kaynak operatörünün uzmanlığı vb. gibi faktörlere bağlı olarak değiştiği söylenebilir. Parametrelerin tekil analizinde, enerji parametresinin sertlik üzerinde \%32,25 oranında, tel besleme hızının ise \%53,29 oranında etkili olduğu belirlenmiştir (Tablo 4 - \% Etki). İstatistiki anlamlılık değerlerine göre de, sadece tel besleme hızı sertlik değerleri üzerinde istatistiki olarak anlamlı sonuç vermektedir (Tablo 4 - p). Tel besleme hızının artmasıyla kaynak bölgesine ilave edilen tel miktarı artacağı için birim alanda daha yoğun malzeme birikimi oluşmaktadır. Bu durumda tel besleme hızının artışı sertlik değerinin yüksek oranda değişimine sebebiyet vermektedir.

Tablo 4. ANOVA sonuçlart.

\begin{tabular}{cccccc}
\hline $\begin{array}{c}\text { Varyansin } \\
\text { Kaynağ }\end{array}$ & $\begin{array}{c}\text { Serbestlik } \\
\text { Derecesi }\end{array}$ & $\begin{array}{c}\text { Kareler } \\
\text { Toplamı }\end{array}$ & $\begin{array}{c}\text { Ortalama } \\
\text { Kareler }\end{array}$ & \% Etki & $\mathrm{p}$ \\
\hline Enerji (J) & 2 & 4754 & 2376,8 & 32,25 & 0,096 \\
\hline $\begin{array}{c}\text { Tel Besleme } \\
\text { Hızı }(\mathrm{mm} / \mathrm{s})\end{array}$ & 2 & 7857 & 3928,4 & 53,29 & 0,046 \\
\hline Hata & 4 & 2132 & 533,1 & 14,46 & - \\
\hline Toplam & 8 & 14743 & - & 100 & - \\
\hline & R-Sq: \% 85,54 & & Adj R-Sq: \% 71,07 & \\
\hline
\end{tabular}

Enerji ve tel besleme hızı parametrelerine göre sertlik değerinin değişimini analiz etmek için Taguchi metodundan yararlanılmış ve sinyal/gürültü $(\mathrm{S} / \mathrm{N})$ oranı grafiği elde edilmiştir. Şekil 5'e göre kaynak bölgesine enerji girişi arttıkça kaynak bölgesinin sertlik değeri düşmektedir. Kaynak bölgesine enerji girişi arttıkça kaynak bölgesi daha fazla isınacak, bu sebeple de kaynak işlemi sonrası soğuma daha geç olacaktır. Soğuma hızının düşmesi tane büyümesine sebebiyet verdiği için sertlik değerleri de düşmektedir. Sertlik düşüşüne sebep olarak yumuşak ve kabalaşmış fazlar gösterilebilir [2]. Şekil 6'da, 50,76 ve 119,34 kJ enerji girişi ile yapılan kaynak işlemleri sonrası oluşan mikroyapılar görülmektedir. 119,34 kJ enerji girişinde oluşan tane yapıs1 50,76 kJ enerji girişinde oluşan mikroyapıya göre daha yaygın ve kabalaşmış olarak gözükmektedir. Bu durum literatür çalışmalarıyla uyum göstermektedir [12].

Kaynak bölgesine verilen ergime enerjisi yeterli olduğu müddetçe ana malzemeler ile kaynak telinin kompozit bir yapı oluşturması beklenmektedir. Tel besleme hızı arttıkça kompozit yapı içerisindeki kaynak teli miktarı da artacaktır. Kaynak telinin akma mukavemet değeri (460 MPa) hem AISI 304'ten hem de S235JR'den daha yüksek, çekme mukavemeti (680 MPa) de AISI 304'e eşdeğer ve S235JR'den yaklaşık 2 kat yüksektir. Bu durum kaynak telinin, kompozit yapının mukavemetini arttırabilecek nitelikte olduğunu göstermektedir. Elde edilen sonuçlar da bu yaklaşımın doğruluğunu kanıtlar niteliktedir. Şekil 7'ye göre tel besleme hızı arttıkça kaynak bölgesi sertliği de artmaktadır. 7 $\mathrm{mm} / \mathrm{s}$ hızdan $12 \mathrm{~mm} / \mathrm{s}$ hıza çıkıldığında sertlik değerlerinde çok düşük oranda artış gözlenmiş, fakat 12 $\mathrm{mm} / \mathrm{s}^{\prime}$ den $18 \mathrm{~mm} / \mathrm{s}$ hıza çıkıldığında sertlik değeri ciddi oranda artmıştır. Bu durum kompozit malzeme içerisindeki malzeme yoğunluğu ile açıklanabilir. Şekil 8'de farklı hızlarda oluşan malzeme yoğunluklarını gösteren mikroyapı görüntüleri verilmiştir. $7 \mathrm{~mm} / \mathrm{s}$ ve $12 \mathrm{~mm} / \mathrm{s}$ hızda oluşan kompozit 
içerisindeki kaynak teli yoğunluğu AISI 304 ve S235JR'ye nazaran daha düşük oranda kalmış, kaynak teli ana malzemelere baskın gelememiştir. $12 \mathrm{~mm} / \mathrm{s}$ hızdan sonra ise kompozit içerisinde kaynak teli yoğunluğu baskın hale gelmiş ve sertlik değeri yüksek oranda artmıştır.

Şekil 5 ve 7'den elde edilen sonuçlara göre AISI 304 ve S235JR malzemenin kaynağında optimum parametreler, minimum enerji girişi $(50,76 \mathrm{~kJ})$ ve maksimum tel besleme hızı $(18 \mathrm{~mm} / \mathrm{s})$ olarak belirlenmiştir. $\mathrm{Bu}$ durum kaynak bölgesine yeteri kadar enerji girişi sağlandıktan sonra (ergimenin sağlandığı minimum enerji değeri), kaynak bölgesinde sağlanacak enerji artışının sertlik değerini olumsuz etkilediği sonucunu ortaya çıkarmaktadır. Bu sebeple kaynak bölgesinin ergimesi için gereken enerji miktarı belirlendikten sonra daha yüksek akım ve voltaj değerlerinde kaynak işleminin yapılması daha fazla enerji tüketimine sebebiyet verecek ve sadece kaynak süresini azaltıcı etki gösterecektir.

Elde edilen sonuçların istatistiki olarak güvenilirliğini doğrulamak için tel besleme hızı ve kaynak enerjisi parametrelerinin $\mathrm{S} / \mathrm{N}$ oranlarına göre etkileşim grafikleri elde edilmiş ve Şekil 9'da verilmiştir. Şekil 9'a göre tel besleme hızı arttıkça ve enerji azaldıkça kaynak bölgesi sertliği artmaktadır. Tane büyümesi ve kompozit malzeme yoğunluğu ile açıklanan deneysel sonuçlar ile etkileşim grafiğinden elde edilen sonuçlar birbirleriyle tutarlılık göstermektedir.

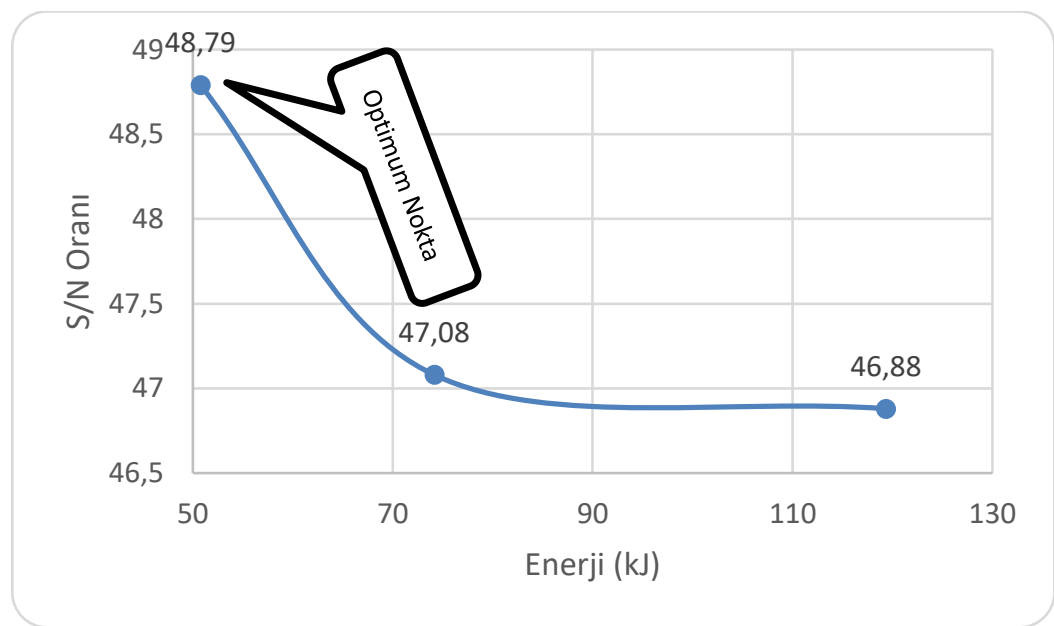

Şekil 5. Kaynak bölgesine enerji girişi için hesaplanmış $S / N$ oranları

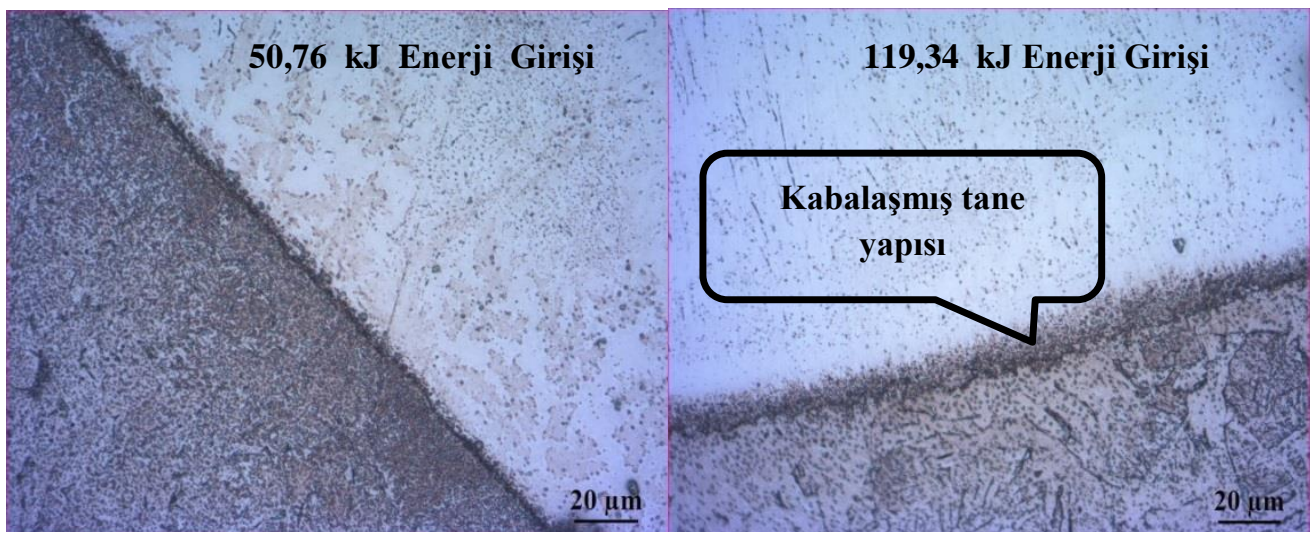

Şekil 6. Farklı kaynak bölgesi enerji değerlerinde oluşan mikroyapı görüntüleri 


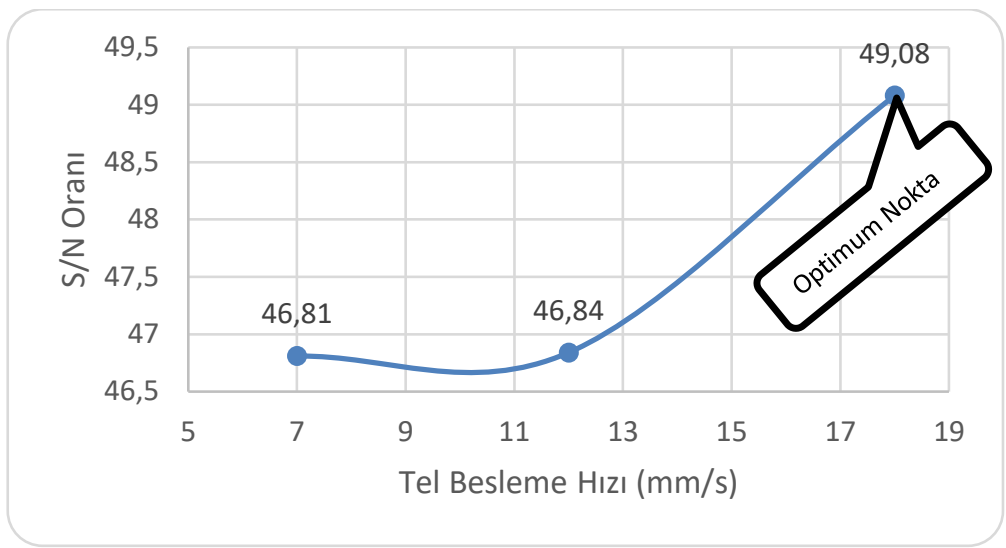

Şekil 7. Tel besleme hızı için hesaplanmış için hesaplanmış S/N oranları

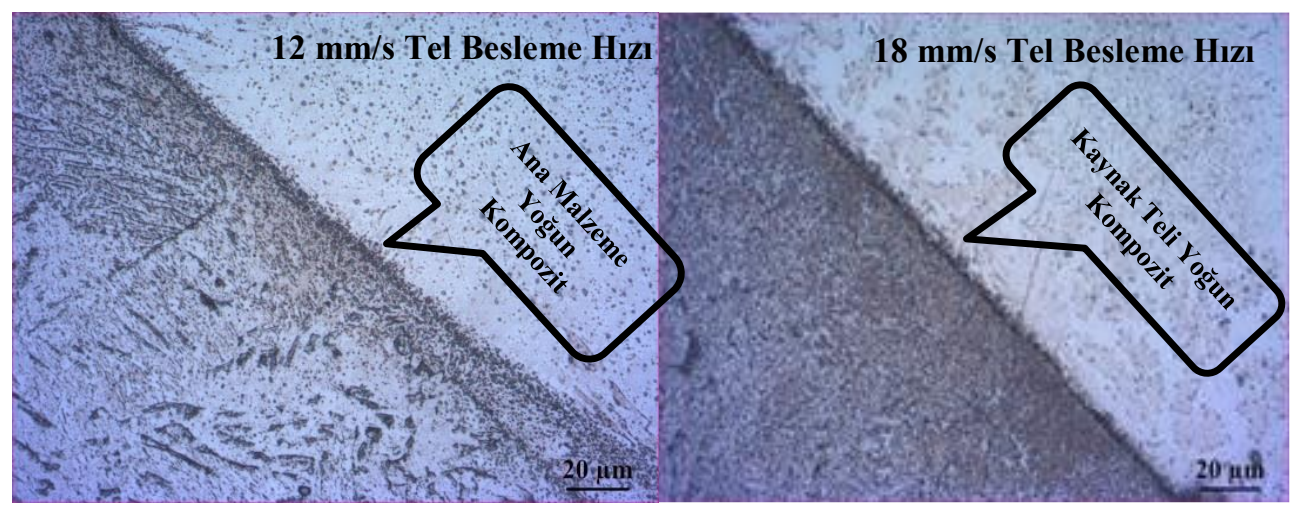

Şekil 8. Farklı tel besleme hızlarında mikroyapı görüntüleri

Elde edilen sonuçların istatistiki olarak güvenilirliğini doğrulamak için tel besleme hızı ve kaynak enerjisi parametrelerinin $\mathrm{S} / \mathrm{N}$ oranlarına göre etkileşim grafikleri elde edilmiş ve Şekil 9'da verilmiştir. Şekil 9'a göre tel besleme hızı arttıkça ve enerji azaldıkça kaynak bölgesi sertliği artmaktadır. Tane büyümesi ve kompozit malzeme yoğunluğu ile açıklanan deneysel sonuçlar ile etkileşim grafiğinden elde edilen sonuçlar birbirleriyle tutarlılık göstermektedir.

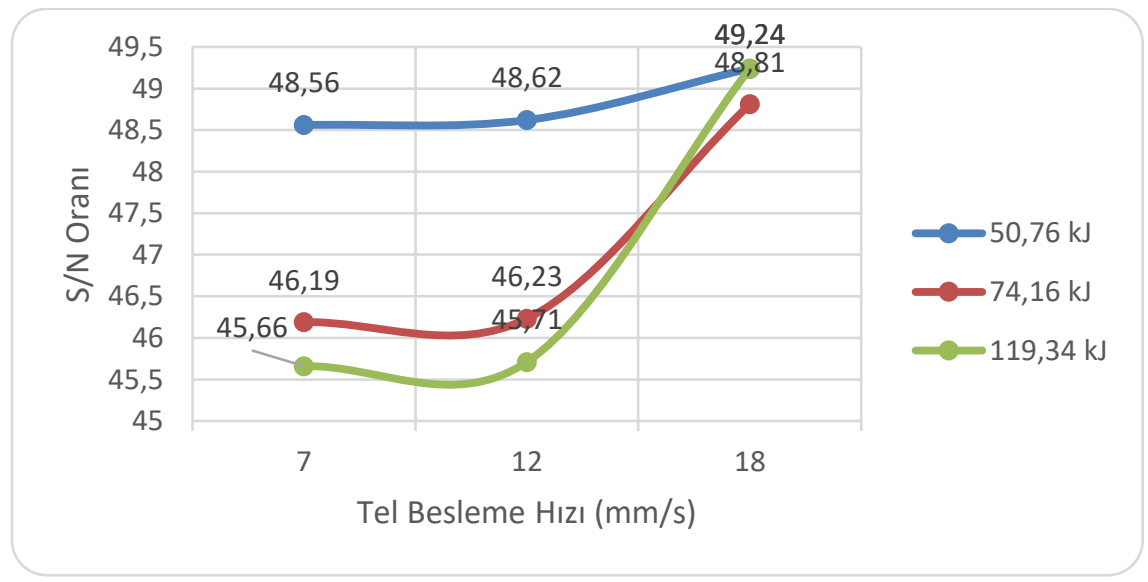

Şekil 9. Tel besleme hızı ve kaynak enerjisinin etkileşim grafiği 


\section{SONUCLLAR}

S235JR düşük karbonlu çelik ile AISI 304 paslanmaz çeliğin, farklı kaynak parametrelerinde MIG kaynak yöntemiyle birleştirildiği bu çalışmanın sonucunda aşağıda belirtilen sonuçlar elde edilmiştir.

- Kaynaklı numunelere uygulanan çekme deneyi sonucunda kaynak bölgesi dayanımının düşük karbonlu çelik malzemeden daha yüksek olduğu görülmüş ve deformasyonun kaynak bölgesinde değil, düşük karbonlu çelik malzeme bölgesinde meydana geldiği tespit edilmiştir. Bu durum AISI 304 ile S235JR malzemenin kaynak edilebilirliğinin mümkün olduğunu göstermektedir.

- Kaynak edilebilirlikte, tel besleme hızı istatistiki açıdan \%53'lük etki oranıyla kaynak bölgesi enerjisi (\%32) parametresinden daha etkilidir.

- Analiz sonuçları incelendiğinde tel besleme hızı arttıkça ve enerji girişi azaldıkça kaynak bölgesi sertliğinin arttığı tespit edilmiştir.

- $50,76 \mathrm{~kJ}$ enerji girişi ve $18 \mathrm{~mm} / \mathrm{s}$ tel besleme hızı değerlerinin maksimum sertliğin elde edilebilmesi açısından optimum parametreler olduğu belirlenmiş ve bu değerlerde AISI 304 paslanmaz çeliği ile S235JR düşük karbonlu çeliğinin güvenli bir şekilde birleştirilebildiği görülmüştür.

- Mikroyapı çalışmaları sonucunda kaynak bölgesine enerji girişi (1sı enerjisi girişi) arttıkça kaynak bölgesinde tane büyümesinin gerçekleştiği görülmüş ve bu durumun sertliği azalttı̆̆ tespit edilmiştir. Bu sebeple $90 \mathrm{~A}$ akım ve $18,8 \mathrm{~V}$ voltaj değerlerinin üstünde çalışılması hem kaynak bölgesinin mekanik özelliklerini olumsuz etkilemesi hem de enerji verimliliği açısından anlamlı değildir.

\section{KAYNAKLAR}

[1] M. Ayvaz ve H. Çetinel, "Farklı Alüminyum Alaşımlarının TIG Kaynak Yöntemiyle Kaynatılmas1 ve Mekanik Özelliklerin İncelenmesi," Celal Bayar University Journal of Science, c.7, s.1, 2011.

[2] S. K1lıçer ve N. Kahraman, "AISI 409 ve Ç1010 Çeliğin Östenitik Elektrod Kullanarak MIG Kaynak Yöntemi ile Birleştirilmesi ve Mekanik Özelliklerinin Araştırılması,” Gazi Üniversitesi Mühendislik-Mimarlık Fakültesi Dergisi, c.24, s.1, 2009.

[3] T. I. Ramjauna, H. J. Stonea, L. Karlssonb, M. Gharghouric, K. Dalaeid, R. Moate, H. K. D. H. Bhadeshiaa, "Surface residual stresses in multipass welds produced using low transformation temperature filler alloys," Science and Technology of Welding and Joining, vol.19, no.7, pp. 623-630, 2014.

[4] P. Ujjvalkumar Arvindbhai, "Optimization of Process Parameter in MIG Welding Process on Dissimilar Material by Using Artificial Neural Network," Master's thesis, Department of Mechanical Engineering, Ganpat University, Gujarat, India, 2015. 
[5] K. Pawan and B. K. Roy, "Parameters Optimization for Gas Metal Arc Welding of Austenitic Stainless Steel (AISI 304) \& Low Carbon Steel using Taguchi's Technique," International Journal of Engineering and Management Research (IJEMR), vol.3, no.4, pp. 18-22, 2013.

[6] S.P Tewari, A. Gupta and J. Prakash, "Effect of welding parameters on the weldability of material," International Journal of Engineering Science and Technology, vol.2, no.4, pp.512-516, 2010.

[7] N. Kahraman, B. Gülenç ve H. Akça, "Ark kaynak yöntemi ile birleştirilen ostenitik paslanmaz çelik ile düşük karbonlu çeliğin mekanik özelliklerinin incelenmesi," Gazi Üniversitesi Mühendislik-Mimarlık Fakültesi Dergisi, c.17, s.2, 2002.

[8] B. F. Jogi, A. S. Awale, S. R. Nirantar, H. S. Bhusare, "Metal Inert Gas (MIG) Welding Process Optimization using Teaching-Learning Based Optimization (TLBO) Algorithm," Materials Today: Proceedings, vol.5, no.2, 7086-7095, 2018.

[9] M. D. Prasad and K. Kumar Namala, "Process Parameters Optimization in Friction Stir Welding by ANOVA,” Materials Today: Proceedings, vol.5, no.2, pp. 4824-4831, 2018.

[10] L. Zhou, J. Min, W. X. He, Y. X. Huang, X. G. Song, "Effect of Welding Time on Microstructure and Mechanical Properties of Al-Ti Ultrasonic Spot Welds," Journal of Manufacturing Processes, vol. 33, pp. 64-73, 2018.

[11] N. Ghosh, R. Rudrapati, P. K. Pal, G. Nandi, "Parametric Optimization of Gas Metal Arc Welding Process by using Taguchi method on Ferritic Stainless Steel AISI409," Materials Today: Proceedings, vol.4, no.2, pp. 2213-2221, 2017.

[12] M. Eroğlu ve M. Aksoy "Enerji girişinin kaynak metali mikroyapısı ve mekanik özellikleri üzerine etkisi," Bilim Günleri Bildiriler Kitabı, Makina Mühendisleri Odası, Denizli, Türkiye, ss. 434439, 1999. 